Kansas State University Libraries

New Prairie Press

\title{
A COMPARISON OF MODELS AND DESIGNS FOR EXPERIMENTS WITH NONLINEAR DOSE-RESPONSE RELATIONSHIPS
}

Shengjie Guo

W. W. Stroup

E. T. Paparozzi

M. E. Conley

See next page for additional authors

Follow this and additional works at: https://newprairiepress.org/agstatconference

Part of the Agriculture Commons, and the Applied Statistics Commons

\section{(c) (1) $\Theta$}

This work is licensed under a Creative Commons Attribution-Noncommercial-No Derivative Works 4.0 License.

\section{Recommended Citation}

Guo, Shengjie; Stroup, W. W.; Paparozzi, E. T.; and Conley, M. E. (2006). "A COMPARISON OF MODELS AND DESIGNS FOR EXPERIMENTS WITH NONLINEAR DOSE-RESPONSE RELATIONSHIPS," Conference on Applied Statistics in Agriculture. https://doi.org/10.4148/2475-7772.1128

This is brought to you for free and open access by the Conferences at New Prairie Press. It has been accepted for inclusion in Conference on Applied Statistics in Agriculture by an authorized administrator of New Prairie Press. For more information, please contact cads@k-state.edu. 


\section{Author Information}

Shengjie Guo, W. W. Stroup, E. T. Paparozzi, and M. E. Conley 


\title{
A COMPARISON OF MODELS AND DESIGNS FOR EXPERIMENTS WITH NONLINEAR DOSE-RESPONSE RELATIONSHIPS
}

\author{
Shengjie Guo, Department of Mathematics, University of Nebraska, Lincoln \\ W.W. Stroup, Department of Statistics, University of Nebraska, Lincoln \\ E.T. Paparozzi, Department of Agronomy and Horticulture, University of Nebraska, \\ Lincoln \\ M.E. Conley, Department of Agronomy and Horticulture, University of Nebraska, Lincoln
}

ABSTRACT: Research investigating dose-response relationship is common in agricultural science. Animal response to drug dose and plant response to amount of irrigation, pesticide, or fertilizer are familiar examples. This paper is motivated by plant nutrition research in horticulture. Plant response to level of nutrient applied is typically sigmoidal, i.e. no response at very low levels, observable response at mid-levels, point-of-diminishing returns and plateau at high levels. Plant scientists need accurate estimates of these response relationships 1) to determine lower threshold below which plants show deficiency symptoms and 2) to determine upper point-of-diminishing returns, above which excessive doses are economically and environmentally costly. Landes, at al. (1999 and Olson et al. (2001) did initial work identifying potentially useful models. Paparozzi, et al. (2005) investigated dose (micro- and macro-nutrient) response (elemental leaf and stem concentration) relationships in Poinsettia. They found that 1) nutrients must be considered as a system, hence multifactor experiments are essential, 2) resources are limited, meaning that experiments must use response-surface principles, and 3) nutrient-response relationships are rarely modeled adequately by $2^{\text {nd }}$ order polynomial regression models, so standard response surface methods are inadequate. This paper presents models and designs that address these requirements and a simulation study to assess and compare the small-sample behavior of these models and designs.

KEY WORDS: response surface, nonlinear regression, linear plateau, central composite design, face centered cube design, D-optimality, Hoerl model, Gompertz model, Mitscherlich model

\section{Introduction}

Agricultural researchers frequently want to characterize the effect of two or more quantitative factors. Familiar examples include the effect of nutrient levels on animal growth, the effect of pesticides on weed or insect control, the effect of irrigation and fertilization level on crop yield, the effect of drug dosage on animal health or performance, and so forth. In the vast majority of cases, quantitative factors act as systems; interaction among the factors is the rule, not the exception, so these studies usually must be conducted using factorial designs. In agriculture, these experiments face additional constraints imposed primarily by two realities: first, the experiments must be conducted over a fixed period (e.g. a plant's growing season or the time it takes an animal to grow to maturity); and second, the amount of experimental material (e.g. plants or animals) is limited, often severely so.

A typical case, which will be used as a working example in this paper, occurs in plant nutrition, illustrated by Figure 1. An ornamental horticulturist wants to understand the effects on Poinsettia of varying the levels at which several elemental nutrients (in this case, N, S, Fe, and 
$\mathrm{Mn})$ are applied. The plants in Figure 1 are arranged by increasing level of $\mathrm{N}$ along one axis and increasing level of S along the other axis (within each 3x3 square are the levels of Fe and Mn, although their effects are more subtle). One can see that at low application levels of either $\mathrm{N}$ or $\mathrm{S}$, the plants do not perform well (they are pale), but as the level of $\mathrm{N}$ and $\mathrm{S}$ increases, the plants performance improves (they appear darker). One can also see that there is a point of diminishing returns, above which increasing $\mathrm{N}$ or $\mathrm{S}$ levels do not improve plant performance. The researcher's goal is to determine the optimum combination of nutrients to apply, where optimum is defined as the lowest level of nutrient that can be applied and still achieve the desired plant performance. If the nutrient levels applied are too low, deficiency symptoms (whose visual evidence is the pale plants) will occur. On the other hand, excessive nutrient application may result in environmental damage or economic losses to the grower. Variations on this theme occur throughout agricultural research. It is basically a dose-response problem.

Clearly, this type of problem calls for some form of response surface approach, both in terms of modeling the dose-response relationship and in terms of designing an efficient experiment. At first blush, one might think that response surface methodology, as covered in any number of excellent texts (Box, Hunter and Hunter, 1978; Cornell and Khuri, 1996; Myers and Montgomery, 2002), would effectively address the problem. However, there are a number of reasons why standard response surface methodology is inadequate for such problems. From a response surface viewpoint, Figure 1 can be characterized by the two-dimensional plot shown in Figure 2.

Figure 2 shows a typical agricultural dose-response situation. Both $\mathrm{N}$ and $\mathrm{S}$ are limiting, i.e. low doses of either yield poor performance regardless of the dose of the other factor. Also, at non-limiting levels of one factor, the response to the other factor increases with dose to a point of diminishing returns, above which further increases in dose produce no additional response. Standard response surface methodology assumes that $2^{\text {nd }}$ order polynomial regression can adequately characterize the response surface. In general, the $2^{\text {nd }}$ order polynomial regression model can be written as

$$
E(y)=\beta_{0}+\sum_{i} \beta_{i} X_{i}+\sum_{i} \beta_{i i} X_{i}^{2}+\sum_{i<j} \beta_{i j} X_{i} X_{j} \text {, where }
$$

$E(y)$ denotes the expected value of the response,

$\beta_{0}$ denotes the intercept,

$X_{i}$ denotes the level of the $i^{\text {th }}$ quantitative factor (e.g. $\mathrm{N}$ or $\mathrm{S}$ ),

$\beta_{i}$ denotes the linear regression coefficient for the $i^{\text {th }}$ quantitative factor,

$\beta_{i i}$ denotes the quadratic regression coefficient for the $i^{\text {th }}$ quantitative factor,

$\beta_{i j}$ denotes the linear $\times$ linear regression coefficient for the interaction between the $i^{\text {th }}$ and $j^{\text {th }}$

quantitative factors

For response profiles such as Figure 2, there are two main problems. First, the interactions among factors are more complex. For example, a linear $\times$ linear term cannot adequately characterize the interaction resulting from the fact the both $\mathrm{N}$ and $\mathrm{S}$ are limiting. Second, $2^{\text {nd }}$ order polynomial model assumes that a quadratic regression is adequate to characterize the 
response over any given factor. With Figure 2, the quadratic assumption fails, as shown in Figure 3.

In Figure 3, the "true 'optimal' dose" occurs at the point on the X-axis where the actual response, shown by the boldface dashed line, ceases to increase and forms a plateau for all greater doses. In contrast, the quadratic model estimates the maximum response to occur at a much higher dose level. Note also that the quadratic model overestimates the maximum response. From a practical viewpoint, this means that the quadratic model would mislead a grower into using more nutrient that necessary. Excessive nutrient application could have serious economic or environmental consequences. This is, in part, why Mead and Pike (1975), in a survey of the use of response surface methods in agriculture, found that non-use of such methods was widespread.

What models are capable of adequately characterizing Figure 2? Anderson and Nelson (1975) described "linear plateau" models, essentially spline or segmented regressions similar to the "true" response pictured in Figure 3. This approach works well with one nutrient at a time experiments, but is harder to work with in multi-factor experiments. More importantly, the linear plateau approach is not conducive to efficient design selection, an important aspect of the Poinsettia example discussed below. Nonlinear models offer an alternative. In previous Applied Statistics in Agriculture conferences, Landes, et al. (1999) and Olson, et al. (2001) presented the foundations of this paper's approach. Landes, et al. (1999) presented adaptations of Gompertz and Mitscherlich nonlinear models to fit plant nutrition data from Macz et al. (1997). For the purposes of multifactor data, the Gompertz and Mitscherlich models, respectively,

$E(y)=\alpha \times \exp \left[\beta \times \exp \left(-\sum_{i} \gamma_{i} X_{i}-\sum_{i<j} \gamma_{i j} X_{i} X_{j}-\sum_{i<j<k} \gamma_{i j k} X_{i} X_{j} X_{k}-\ldots\right)\right]$, where

$E(y)$ and $X_{i}$ are defined as above,

$\alpha$ denotes the asymptote,

$\beta$ denotes the log of proportion of the asymptote that $E(y)$ increases from $X_{i}=0$ to the values of $X_{i}$ at which $E(y)$ is effectively at asymptote, and

$\gamma_{i}, \gamma_{i j}, \gamma_{i j k}, \ldots$ denote the rates of increase associated with the $i^{\text {th }}$ main effects, $i j^{\text {th }}$ two-way interactions, $i j k^{\text {th }}$ three-way interactions, etc. While not shown explicitly in the model equation, up to $n$-way interactions can be included for $n$-factor factorial experiments.

The Mitscherlich is

$$
E(y)=\alpha-\beta\left(\prod_{i} \gamma_{i}^{X_{i}} \prod_{i<j} \gamma_{i j}^{X_{i} X_{j}} \prod_{i<j<k} \gamma_{i j k}^{X_{i} X_{j} X_{k}} \ldots\right)
$$

where all the terms in the model have meanings analogous to the Gompertz.

For a single factor, the Gompertz and Mitscherlich have similar plots, shown in Figure 4. One can easily see that the accuracy of the model fit is vastly improved.

Olson, et al. (2001) suggested an alternative nonlinear model, the Hoerl model. The basic form of the Hoerl model is $E(y)=\exp \left(\beta_{0}+\beta_{1} X\right)\left[X^{\beta_{2}}\right]$, which can be expressed in linearized form as $\ln [E(y)]=\beta_{0}+\beta_{1} X+\beta_{2} \ln (X)$. For multifactor experiments, the linearized Hoerl is 


$$
\begin{gathered}
\ln [E(y)]=\beta_{0}+\sum_{i}\left[\beta_{1 i} X_{i}+\beta_{2 i} \ln \left(X_{i}\right)\right]+\sum_{i<j}\left[\beta_{1 i j} X_{i} X_{j}+\beta_{2 i j} \ln \left(X_{i}\right) \ln \left(X_{j}\right)\right] \\
+\sum_{i<j<k}\left[\beta_{1 i j k} X_{i} X_{j} X_{k}+\beta_{2 i j k} \ln \left(X_{i}\right) \ln \left(X_{j}\right) \ln \left(X_{k}\right)\right]+\ldots
\end{gathered}
$$

$\beta_{0}$ denotes the intercept,

$\beta_{1 i}, \beta_{1 i j}, \beta_{1 i j k}, \ldots$. denote main effect, 2-way interaction, 3-way interaction, etc. coefficients associated with the literal levels, $X_{i}$, of the $i^{\text {th }}$ factor, and

$\beta_{2 i}, \beta_{2 i j}, \beta_{2 i j k}, \ldots$ denote main effect, 2-way interaction, 3-way interaction, etc. coefficients associated with the log levels, $\ln \left(X_{i}\right)$, of the $i^{\text {th }}$ factor.

Figure 5 shows the single-factor fit of the Hoerl model relative to our working example. The fit is somewhat less exact than the Gompertz or Mitscherlich. However, the advantage of the Hoerl model is that, in its linearized form, it can be fit with linear model software and, as will be shown below, efficient, robust designs can be generated by optimizing them for the Hoerl. Thus, the Hoerl model is a good compromise between accurate fit and versatility.

Paparozzi, et al. (2005) evaluated the fit of alternative models over 20 plant responses, mostly elemental concentration, in a 4-factor (N, S, Fe, and $\mathrm{Mn}$ ) poinsettia nutrition experiment. In most cases, the $2^{\text {nd }}$ order polynomial regression model showed strong evidence of lack of fit, whereas the Hoerl model fit adequately in most cases. The main reasons for inadequate $2^{\text {nd }}$ order polynomial fit were the inadequacy of the quadratic (as in Figure 3) or the existence of interactions of higher than $2^{\text {nd }}$ order. The Gompertz and Mitscherlich models fit well when the response was of the diminishing returns form as shown in Figure 2.

Failure of the $2^{\text {nd }}$ order polynomial is not unique to agriculture. Standard response surface methods deal with this problem by restricting the range of the $X_{i}$ values to small subsets of the total experimental region so that the $2^{\text {nd }}$ order approximation is acceptable within the subset. Researchers use a succession of such experiments to search the experimental region for the optimal treatment combination. While this approach works well in engineering and other applications that permit running a number of experiments in quick succession, it is not wellsuited to agriculture, where the experiment must conform to the length of the growing season, the time it takes an animal to grow to maturity, or whatever time scale is relevant. Agricultural researchers need response surface methods that can produce usable information from a single experiment (especially when the research is for a graduate student thesis or an untenured assistant professor).

The final reality that agricultural researchers face is an upper limit on the number of experimental units that can be handled in a single experiment. For example, with resources likely to be available, the effective upper limit on the size of Poinsettia experiments such as the one illustrated in Figure 1 is roughly 100-125 plants. This upper limit is typical of agricultural research.

In summary, the agricultural response surface problem is characterized by four basic, mutually contradictory needs:

1. Factorial treatment designs are essential. Agricultural treatment factors can rarely be studied out of context of the treatment systems within which they are used. Interactions are the rule, not the exception.

2. Models more complex than $2^{\text {nd }}$ order polynomial regression are often essential to adequately describe the dose-response relationship. 
3. The number of experimental units available in a single experiment is often severely constrained.

4. Running a succession of small experiments to search the experimental region is usually not an option.

Olson, et al. (2001) proposed a design approach for such experiments. The basic idea is that standard response surface designs - e.g. Central Composite designs, Box-Behnken designs, fractions of $3^{\mathrm{N}}$ factorial designs - are inadequate but they can be augmented to more realistically address the four needs listed above. As an example for a three-factor experiment, Olson presented a possible design based on the "Face Centered Cube" essentially a Central Composite design with "face" points instead of axial points. Figure 6 shows the design. Olson named this design as the "CELEPSO" design - we will henceforth refer to it as an "augmented face centered cube.”

The augmented face centered cube design assumes five levels of each of three factors (labeled 0, 1, 2, 3, and 4). Olson, et al. used five levels to guarantee that one would be able to estimate a nonlinear response surface model such as the Gompertz or Mitscherlich. The "face centered cube" uses levels 0,2 , and 4: a $2^{3}$ factorial using levels 0 and 4 plus six "face points (level 2 of any two factors in conjunction with either level 0 or 4 of the third factor) and a center point (level 2 of all three factors). Embedded within the face centered cube is a $2^{3}$ factorial using levels 1 and 3 . This design thus requires a total of 23 treatment combinations (out of $5^{3}=125$ possible factorial combinations) but would permit estimation of the Hoerl, Gompertz, or Mitscherlich models.

Although the augmented face-centered cube appears to be a usable design and the Hoerl, Gompertz, or Mitscherlich models appear to be capable of accurately characterizing typical agricultural multi-factor dose-response relationships, several questions remain. The two questions of specific interest in this paper are

1. How does the augmented face centered cube design perform in practice and are there alternative designs that might be better?

2. What are the various models' small-sample behaviors? What is their relative accuracy and precision? For the Gompertz and Mitscherlich models, is one likely to experience difficulty obtaining accurate parameter estimates when the data are from incomplete factorial response surface designs such as the augmented face centered cube?

The primary purpose of this paper is to address these twin objectives. In Section Two, alternative designs are developed. Section Three reports on a simulation study exploring the small sample behavior of the model-design combinations developed in sections one and two.

\section{Response Surface Designs for Nonlinear Dose-Response Models}

In Section One, the quadratic, Hoerl, Gompertz, and Mitscherlich models were compared in Figures 3 through 5 for their fit relative to the "diminishing returns" dose-response model over a single factor. To compare designs in multi-factor experiments, we need to view these models in a multifactor context. In the two-factor case, the Hoerl model has an additional interaction term $(\log \times \log )$ not present in the $2^{\text {nd }}$ order polynomial. In three- and higher-way models, the Hoerl, Gompertz, and Mitscherlich models have three- and higher-way interaction terms as well. Obviously, if complex interaction (i.e. any interaction more complex than linear $\times$ linear twoway interaction) is present, the Hoerl and nonlinear (Gompertz and Mitscherlich) models should 
perform better. Figures 7-9 show the fits of $2^{\text {nd }}$ order polynomial, Hoerl, and Gompertz models, respectively, for a three-factor extension of the surface shown in Figure 2. Suppose that all three factors are limiting, so that at the lowest level of any factor, the surface for the other two factors is flat. At higher levels of any factor, the surface for the other two factors looks like Figure 2. Figures 7-9 show the fits at the highest level of the third factor, so the ideal against which to compare them is Figure 2. The Mitscherlich is not shown, but for this example is virtually indistinguishable from the Gompertz.

One can see that the Hoerl and Gompertz model provide obviously more accurate fits. However, one could reasonably ask if the polynomial model were augmented to contain complex interaction terms analogous to those in the multifactor Hoerl, Gompertz, and Mitscherlich models as given in Section One, how would the fit compare? An augmented polynomial would contain quadratic $\times$ quadratic terms in place of the $\log \left(X_{i}\right) \times \log \left(X_{j}\right)$ terms in the Hoerl model as well as linear $\times$ linear $\times$ linear and quadratic $\times$ quadratic $\times$ quadratic three-way interaction terms. The resulting fit is shown in Figure 10.

One can see that while the fit is certainly better than the $2^{\text {nd }}$ order polynomial, it is still inferior to the Hoerl and Gompertz. The polynomial fit could be improved by adding cubic terms, but this is counterproductive in several ways. First, unlike the Hoerl and nonlinear models, higher-order polynomial terms lack direct practical interpretation. Second, higher-order polynomial models are not parsimonious - adding terms to produce a fit that is no better than an alternative with fewer parameters makes no sense. Also, more parameters would in turn necessitate more treatment combinations in the design, counter to the researcher's requirements.

This paragraph sets up the basic attributes of designs required to address our problem. A design capable of producing data to allow estimation of the three-factor Hoerl model must allow for the intercept plus 14 treatment effect parameters (3 linear terms, 3 log main effects, $\left(\begin{array}{l}3 \\ 2\end{array}\right)$ linear $\times$ linear terms, $\left(\begin{array}{l}3 \\ 2\end{array}\right) \log \times \log$ terms, one linear $\times$ linear $\times$ linear term and one $\log \times \log$ $\times \log$ term). A four-factor model would require 4 linear main effects, 4 log main effects, $\left(\begin{array}{l}4 \\ 2\end{array}\right)$ linear two-way terms, $\left(\begin{array}{l}4 \\ 2\end{array}\right) \log$ two-way terms, $\left(\begin{array}{l}4 \\ 3\end{array}\right)$ linear three-way terms, $\left(\begin{array}{l}4 \\ 3\end{array}\right) \log$ threeway terms, one four-way linear and one four-way log term, for a total of 30 treatment effect parameters plus the intercept. Table 1 gives design size characteristics for up to six factor experiments.

Table 1 shows several important results. First, standard response surface designs such as the central composite are inadequate for agricultural response surface experiments with four or more factors, and may be marginal even for three-factor experiments. Second, five factors are probably the upper practical limit for any single study, assuming an upper limit of 100-125 experimental units. Third, experiments of this type have to be regarded as exploratory, as the ability to replicate is limited. For five factors, not every treatment combination could even be replicated in a single experiment.

The rest of this paper will focus on the three-factor case. The augmented face-centered cube is one design that satisfies the requirements shown in Table 1 . What alternative designs could one consider? One approach would be to construct optimal designs (e.g. D-optimal) with respect 
to the models under discussion. Exact D-optimal designs can be constructed with respect to the Hoerl and augmented polynomial models. The method of Box and Lucas (1959) can be used to constructed approximate optimal designs for the Gompertz and Mitscherlich models. We used SAS ${ }^{\circledR}$ PROC OPTEX to obtain these designs. The designs were generated from a candidate set of all 125 possible combinations of three factors with five levels each. The augmented facecentered cube design with 3 replications at the center point was used as an initial design. For the Hoerl and augmented polynomial models, D-optimal designs were generated directly from their respective linear models. The following SAS code was used. Note that X1, X2, and X3 refer to the three factors, each with levels $0,1,2,3$, and 4 . The variables LOGX1, etc. are the natural logs of X1, etc. For the Hoerl model, 0.1 was added to X1, X2 and X3 in order to compute the log. The program:

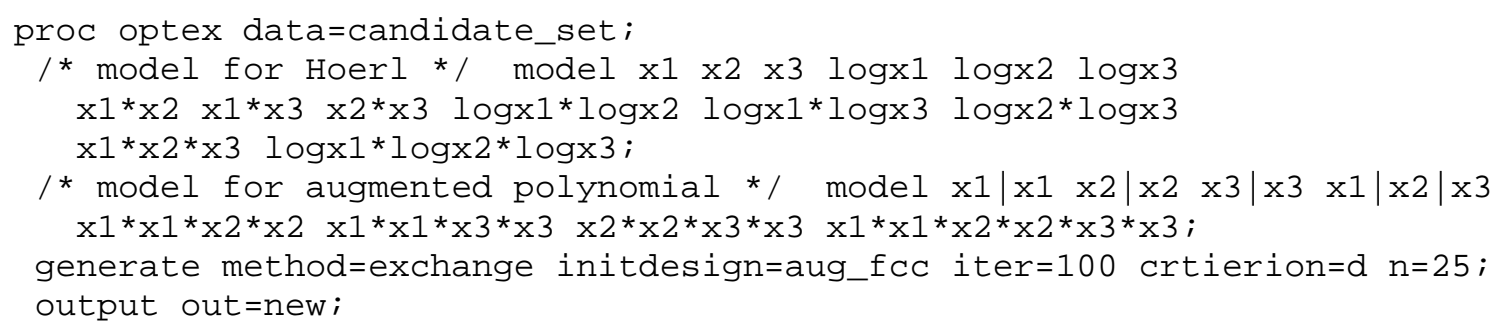

For the Gompertz and Mitscherlich models, approximate optimal designs were generated by obtaining the derivative with respect to each parameter in the model. Each derivative was evaluated at the "true" parameter value for the data depicted in Figure 2 (more information about these data is given below under the description of the simulation study). To save time and effort, one can use the derivative function of PROC NLIN to obtain the derivatives. As an example, for the Gompertz, the OPTEX program was

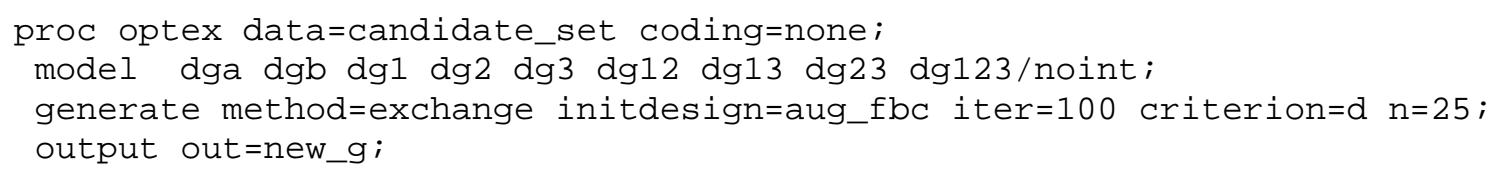

The variables DGA, DGB, DG1, ..., DG123 denote the derivatives with respect to $\alpha$, $\beta$, the $\gamma_{i}(i=1,2,3)$, the $\gamma_{i j}(i<j=1,2,3)$, and $\gamma_{123}$. Note the need for the NOINT option as the procedure would otherwise insert an unwanted intercept, $\beta_{0}$, into the model. For the Gompertz and Mitscherlich approximations, the D-optimal criterion in PROC OPTEX produced obviously flawed designs (see next paragraph). When the U-optimal criterion (CRITERION=U in the GENERATE statement) was used with the Mitscherlich, the resulting design appeared to be more reasonable. Computer assisted design algorithms such as PROC OPTEX can be extremely helpful, but the designs they generate should be examined carefully before using them. Table 2 shows the designs generated as optimal for the various models.

Table 2 reveals some "red flags" for certain designs. For example, the D-optimal design with respect to the augmented polynomial model uses only treatment combinations from levels 0,2 , and 4 of each factor. While this may optimize estimating the polynomial, it may create problems for the nonlinear models if three levels per factor are inadequate for reliable estimation. The approximate D-optimal design with respect to the Gompertz has 19 of the 25 observations at the zero level of at least one factor. Such a design appears flawed by inspection: with only six observations at a non-limiting treatment combination, one wonders if a data set from this design 
can produce a meaningful picture of the response surface. The D-optimal design with respect to the Hoerl only uses four levels per factor, never using level 3, whereas the U-optimal design with respect to the Mitscherlich uses all five levels but without any apparent pattern. Whether these are problems is unclear. The comparisons in the next section will provide answers.

\section{Comparison of Designs}

The designs in section 2 can be compared in one of two ways. First, one can compare them with respect to various design optimality criteria. Second, one can compare them via simulation.

For the comparison with respect to optimality criteria, the Hoerl seems a reasonable choice as a reference model. The justification is as follows. Typical optimality criteria are based on the $\mathbf{X}$ matrix implied by the design. Specifically, D-optimal designs maximize the determinate, $\left|X^{\prime} X\right|$ and A-optimal designs minimize the trace of $\left(X^{\prime} X\right)^{-1}$, that is the average variance of the estimated model parameters. Of the designs under consideration, only the polynomial models ( $2^{\text {nd }}$ order and augmented) and the linearized form of the Hoerl have exact $\mathbf{X}$ matrices and of these, only the Hoerl provides an accurate fit of the surface shown in Figure 2. Table 3 shows the D-optimality (expressed as $\log \left(\left|X^{\prime} X\right|\right)$ and the A-optimality criteria with respect to the Hoerl model for each design under consideration. The central composite design is also shown for the sake of comparison.

One can see from Table 3 that the central composite design, regardless of how replication is approached, is dramatically inferior to the other designs with respect to our working response surface prototype. One can also see that the designs generated with respect to the Gompertz and Mitscherlich models do not compete well with the other designs as far as the Hoerl model is concerned. However, the simulation study is needed to fully understand how these designs will perform when estimating the Gompertz and Mitscherlich models.

\section{Simulation Study}

To study the small sample behavior of the models with data from the designs described in the previous section, a simulation study was conducted. An "ideal” population based on the situation portrayed in Figure 2 was constructed. This population had three factors, each with levels 0, 1, 2, 3 , and 4, where the 0 level for each factor was defined to be "limiting" and level 4 was defined to be the maximum. Figure 11 shows the response characteristic of this "ideal" population. An attached file contains the data set of the ideal population.

For each design, 1500 simulated data sets were generated. For each simulated data set, the $X_{1} \times X_{2} \times X_{3}$ treatment combinations shown in Table 2 were used. Simulated observations were generated by taking the response value in the ideal data set for each given $X_{1} \times X_{2} \times X_{3}$ treatment combination and adding a normal deviate from a normal population with a mean of zero and a variance of 3 . The responses in the ideal population range from 5 for the limiting treatment levels to a maximum of 14 , so the variance corresponds roughly to a $10-20 \%$ coefficient of variation, typical for plant science studies.

Each model was estimated using each simulated data set. The estimated coefficients were then used to compute predicted responses for all $125 X_{1} \times X_{2} \times X_{3}$ treatment combinations in the 
population. The adequacy of each model-design combination was assessed by computing the correlation between the "true" and predicted responses and the sum of squared prediction errors over the $125 X_{1} \times X_{2} \times X_{3}$ treatment combinations. Estimation used PROC GLM for the $2^{\text {nd }}$ order and augmented polynomial models and the Hoerl model. For the Hoerl model, the righthand side of equation (4) was fit to $\log (Y)$ as shown in equation (4) and directly to the response variable, $Y$. This was done to shed light on our experience that applying the right-hand side of the linearized Hoerl directly to $Y$ was producing better results. PROC NLIN was used for the Gompertz and Mitscherlich models. Since PROC NLIN is an iterative procedure, it failed to converge for some of the simulated data sets. As some designs were more prone to nonconvergence than others, the convergence proportion was an additional criterion for the simulation study.

Table 4 shows the results of the simulation study. Figures 12 through 17 show the average fit of the Mitscherlich, Hoerl, and augmented polynomial models over factors X1 and X2 at X3=0 and X3=4. Visually, the Gompertz model fit is virtually indistinguishable from the Mitscherlich. The $2^{\text {nd }}$ order polynomial is not shown, but is basically similar to the grossly inadequate fit shown in Figure 7.

From Table 4, several conclusions emerge. First, the D-optimal design with respect to the Hoerl appears to be the most robust design. The two nonlinear models, Gompertz and Mitscherlich, and the linearized Hoerl with $\mathrm{Y}$, not $\log (\mathrm{Y})$ used as the response variable, all produce results with SS(prediction error) $<200$ and correlation $(Y, \hat{Y})>0.95$. The convergence proportion for each nonlinear model is at or close to $100 \%$. The two nonlinear models perform nearly as well with the augmented face centered cube as with the D-optimal Hoerl design. The Hoerl with $\log (\mathrm{Y})$ as the response variable, the augmented polynomial, and the $2^{\text {nd }}$ order polynomial are worse, in that order. With the D-optimal design with respect to the augmented polynomial, the augmented polynomial model's performance is indeed optimized, but even with this design, its fit is noticeably worse that that the Hoerl and Gompertz, although while the Gompertz has the best fit when it converges, its convergence rate is only 85.3\%. The designs ostensibly optimized for the Gompertz and Mitscherlich in practice perform no better than the Doptimal Hoerl design for their intended models and show severely degraded performance with respect to the other models under investigation. This suggests that a design strategy based on obtaining a D-optimal design with respect to the Hoerl, regardless of the model one ultimately uses to fit the data, is a good all-purpose strategy. The Hoerl model does not require guesses, educated or otherwise, of nonlinear parameters and is far more capable of fitting linear plateau or diminishing returns type response surfaces typical of agricultural research.

Figure 12 through 17 verify that the realized fits using these models with the D-optimal Hoerl response surface design follow the theoretical fits shown in Figures 7-9 very closely. The nonlinear models and the Hoerl, using $\mathrm{Y}$ as the response variable, provide an average fit very close to the actual data, whereas the polynomial, even augmented with terms analogous to the higher-order interaction terms in the Hoerl model, yields a poor and misleading fit.

\section{Discussion}

These results suggest that the nonlinear Gompertz and Mitscherlich models and the linearized form of the Hoerl model used in conjunction with a D-optimal response surface design optimized for the Hoerl provide a good general purpose approach to exploratory investigation of nonlinear, 
diminishing return response surfaces in agriculture when resources are limited. While the simulation study is limited to a specific scenario, it is a typical scenario for many kinds of agricultural research from a variety of disciplines.

Further research underway in this area focuses on several issues. First, we are in the process of verifying that the results for the three-factor case simulated in this paper hold for the fourfactor case. Second, we are looking at alternative scenarios, such as ones of interest observed by Paparozzi, et al. (2005). Third, we are investigating in more detail design optimization for nonlinear models including the question of how many levels and what spacing might improve the estimates of nonlinear models without compromising the Hoerl model. Fourth, we are looking at a wider variety of models, including linear plateau models and possibly logistic models. Finally, we are taking a closer look at the reasons for nonconvergence. In some cases, such as the approximate D-optimal design with respect to the Gompertz generated by PROC OPTEX, the design is obviously flawed and if anything it is surprising that the convergence rates are as high as they are. In other cases, e.g. the U-optimal design that appears to provide excellent performance with the nonlinear models, the convergence rates are around 97\%. Might it be possible with a little tweaking to get the convergence rate up to $100 \%$ ?

In any event, the results presented here clearly demonstrate two things. First, standard response surface methods based on $2^{\text {nd }}$ order polynomial regression really do appear to be unsuited to many agricultural applications, so it should hardly be surprising that they are not used as often as one might expect. Second, with suitable modification, the methods for nonlinear response surface investigation work very well and can be efficient and effective tools for agricultural researchers.

\section{Summary}

This research investigated design and analysis for response surface problems suggested by a plant science example. Specifically the response involves several factors, each of which are limiting, and each of which has a sigmoidal response over the factor levels. Previous work has shown that standard response surface methods provide inadequate characterization of such doseresponse profiles. Nonetheless, the need to accurately characterize these profiles in a single experiment and the limits on the size of such experiments make adaptation of response surface methods essential. The simulation study in this paper provides compelling evidence that incomplete factorial designs from a candidate set with 5 levels per factor, constructed to be Doptimal with respect to the linearized form of a multi-factor Hoerl model, in conjunction with estimates from the Hoerl model or the Gompertz or Mitscherlich nonlinear regression models, provide efficient and accurate characterization of the dose-response relationship illustrated by the plant science example used in this paper.

\section{References}

Anderson, R.L. and L. A. Nelson. 1975. A family of models involving intersecting straight lines and concomitant experimental designs used in evaluating response to fertilizer nutrients. Biometrics. 31: 303-318.

Box, G.E.P., W.G. Hunter, and J.S. Hunter, 1978. Statistics for Experiments, New York: John Wiley \& Sons. 
Box, G.E.P. and J.M. Lucas. 1959. Design of experiments in nonlinear situations. Biometrika 46: 77-90.

Cornell, J.A. and A.I. Khuri. 1996. Response surfaces: Designs and analyses, $2^{\text {nd }}$ Ed. New York: Marcel-Dekker.

Landes, R. D., W. W. Stroup, E. T. Paparozzi and M. E. Conley. 2000. Nonlinear models for multi-factor plant nutrition experiments. pp. 105-119. In: Proceedings $11^{\text {th }}$ Conference on Applied Statistics in Agriculture. Department of Statistics. Kansas State University, Manhattan, KS

Macz, O. 1997. The Effect of Nitrogen and Sulfur Applications on Pot Chrysanthemum Production and Post-Harvest Performance. MS Thesis in Horticulture, University of Nebraska-Lincoln.

Mead, R. and D.J. Pike. 1975. "A review of response surface methodology from a biometric viewpoint.” Biometrics 31: 803-851.

Myers, R.C. and D.M. Montgomery. 2002. Response surface methodology: process and product optimization using designed experiments, $2^{\text {nd }}$ Ed. New York: Wiley-Interscience.

Olson, L. M., W. W. Stroup, E. T. Paparozzi and M. E. Conley. 2001. Model building in multifactor plant nutrition experiments. pp. 183-206. In: Proceedings $12^{\text {th }}$ Conference on Applied Statistics in Agriculture. Department of Statistics. Kansas State University. Manhattan, KS.

Paparozzi, E.T., W.W. Stroup, and M.E. Conley. 2005. How to investigate four-way nutrient interactions in plants: a new look at response surface methods. Journal of the American Society for Horticultural Science, 130: 459-468. 
Table 1. Design size characteristics for Three to Six factors.

\begin{tabular}{|c|c|c|c|c|}
\hline Factors & $\mathbf{5}^{\mathbf{N}}$ Factorial & $\begin{array}{c}\text { Parameters } \\
\text { Needed for } \\
\text { Hoerl* }\end{array}$ & $\begin{array}{c}\text { \# Trt Comb in } \\
\text { Central } \\
\text { Composite } \\
\text { Design }\end{array}$ & $\begin{array}{c}\text { \# Trt Comb in } \\
\text { Augmented } \\
\text { Face Ctr Cube }\end{array}$ \\
\hline 3 & 125 & 14 & 15 & 23 \\
\hline 4 & 625 & 30 & 25 & 41 \\
\hline 5 & 3125 & 62 & 43 & 75 \\
\hline 6 & 15625 & 126 & 77 & 141 \\
\hline
\end{tabular}

* Not including intercept. 
Table 2. Designs generated as Optimal with respect to Models under study.

\begin{tabular}{|c|c|c|c|c|c|c|c|c|c|c|c|c|}
\hline \multirow[b]{2}{*}{ Obs } & \multicolumn{3}{|c|}{ D-optimal wrt Hoerl } & \multicolumn{3}{|c|}{$\begin{array}{l}\text { D-optimal wrt aug- } \\
\text { polynomial }\end{array}$} & \multicolumn{3}{|c|}{$\begin{array}{l}\text { D-optimal wrt } \\
\text { Gompertz }\end{array}$} & \multicolumn{3}{|c|}{$\begin{array}{l}\text { U-optimal wrt } \\
\text { Mitscherlich }\end{array}$} \\
\hline & $\mathrm{X} 1$ & $\mathrm{X} 2$ & X3 & $\mathrm{X} 1$ & $\mathrm{X} 2$ & X3 & $\mathrm{X} 1$ & $\mathrm{X} 2$ & $\mathrm{X} 3$ & $\mathrm{X} 1$ & $\mathrm{X} 2$ & X3 \\
\hline 1 & 0 & 0 & 0 & 0 & 0 & 0 & 0 & 0 & 0 & 0 & 0 & 4 \\
\hline 2 & 0 & 0 & 0 & 0 & 0 & 4 & 0 & 0 & 0 & 0 & 1 & 1 \\
\hline 3 & 0 & 0 & 2 & 0 & 2 & 2 & 0 & 0 & 0 & 0 & 2 & 2 \\
\hline 4 & 0 & 0 & 4 & 0 & 2 & 4 & 0 & 0 & 4 & 0 & 3 & 3 \\
\hline 5 & 0 & 2 & 0 & 0 & 4 & 0 & 0 & 0 & 4 & 0 & 3 & 4 \\
\hline 6 & 0 & 2 & 4 & 0 & 4 & 2 & 0 & 4 & 0 & 0 & 4 & 0 \\
\hline 7 & 0 & 4 & 0 & 0 & 4 & 4 & 0 & 4 & 0 & 0 & 4 & 4 \\
\hline 8 & 0 & 4 & 1 & 2 & 0 & 0 & 0 & 4 & 0 & 1 & 0 & 2 \\
\hline 9 & 0 & 4 & 4 & 2 & 0 & 2 & 0 & 4 & 4 & 1 & 1 & 3 \\
\hline 10 & 1 & 0 & 4 & 2 & 0 & 4 & 0 & 4 & 4 & 1 & 2 & 0 \\
\hline 11 & 1 & 1 & 1 & 2 & 2 & 0 & 0 & 4 & 4 & 1 & 3 & 1 \\
\hline 12 & 1 & 4 & 1 & 2 & 2 & 2 & 1 & 1 & 3 & 2 & 0 & 2 \\
\hline 13 & 1 & 4 & 4 & 2 & 2 & 2 & 1 & 3 & 1 & 2 & 2 & 0 \\
\hline 14 & 2 & 0 & 0 & 2 & 2 & 4 & 3 & 1 & 1 & 2 & 2 & 2 \\
\hline 15 & 2 & 4 & 0 & 2 & 4 & 2 & 3 & 3 & 3 & 3 & 0 & 2 \\
\hline 16 & 4 & 0 & 0 & 2 & 4 & 4 & 4 & 0 & 0 & 3 & 0 & 3 \\
\hline 17 & 4 & 0 & 2 & 4 & 0 & 0 & 4 & 0 & 0 & 3 & 0 & 4 \\
\hline 18 & 4 & 0 & 4 & 4 & 0 & 2 & 4 & 0 & 4 & 3 & 1 & 1 \\
\hline 19 & 4 & 1 & 0 & 4 & 0 & 4 & 4 & 0 & 4 & 3 & 3 & 0 \\
\hline 20 & 4 & 1 & 1 & 4 & 2 & 0 & 4 & 0 & 4 & 4 & 0 & 0 \\
\hline 21 & 4 & 1 & 4 & 4 & 2 & 2 & 4 & 4 & 0 & 4 & 0 & 4 \\
\hline 22 & 4 & 4 & 0 & 4 & 2 & 4 & 4 & 4 & 0 & 4 & 2 & 2 \\
\hline 23 & 4 & 4 & 1 & 4 & 4 & 0 & 4 & 4 & 0 & 4 & 3 & 0 \\
\hline 24 & 4 & 4 & 4 & 4 & 4 & 2 & 4 & 4 & 4 & 4 & 4 & 0 \\
\hline 25 & 4 & 4 & 4 & 4 & 4 & 4 & 4 & 4 & 4 & 4 & 4 & 4 \\
\hline
\end{tabular}


Table 3. A- and D-optimality Criteria for Designs under consideration

\begin{tabular}{|c|c|c|}
\hline $\begin{array}{c}\text { Design } \\
\text { (all designs have } 25 \\
\text { observations) }\end{array}$ & D-opt $\left(\log \left(\left|X^{\prime} X\right|\right)\right)$ & A-opt (trace $\left.\left[\left(X^{\prime} X\right)^{-1}\right]\right)$ \\
\hline $\begin{array}{l}\text { Augmented Face-Centered } \\
\text { Cube }\end{array}$ & 63.7 & 22.0 \\
\hline D-optimal wrt Hoerl & 77.0 & 3.4 \\
\hline D-optimal wrt aug Polynomial & 72.0 & 7.7 \\
\hline D-optimal wrt Gompertz & 49.0 & 14.3 \\
\hline U-optimal wrt Mitscherlich & 42.8 & 150.8 \\
\hline $\begin{array}{c}\text { CCD } \\
\text { (replication at center point } \\
\text { only) }\end{array}$ & 24.9 & 10306 \\
\hline $\begin{array}{l}\text { CCD } \\
\text { (replication at axial points) }\end{array}$ & 29.1 & 8109 \\
\hline $\begin{array}{c}\text { CCD } \\
\text { (replication at corner points) }\end{array}$ & 28.3 & 7922 \\
\hline
\end{tabular}


Table 4. Small sample performance of design-model combinations

\begin{tabular}{|c|c|c|c|c|c|c|}
\hline \multirow[b]{2}{*}{ Model } & \multirow{2}{*}{ Criteria $^{1}$} & \multicolumn{5}{|c|}{ Design } \\
\hline & & $\begin{array}{l}\text { Aug } \\
\text { face } \\
\text { ctr } \\
\text { cube }\end{array}$ & $\begin{array}{l}\text { D-opt } \\
\text { Hoerl }\end{array}$ & $\begin{array}{l}\text { D-opt aug } \\
\text { polynomial }\end{array}$ & $\begin{array}{c}\text { D-opt } \\
\text { Gompertz }\end{array}$ & $\begin{array}{c}\text { U-opt } \\
\text { Mitscherlich }\end{array}$ \\
\hline \multirow[t]{3}{*}{ Gompertz } & sS(p.e.) & 167 & 148 & 163 & 145 & 166 \\
\hline & $\operatorname{Corr}(Y, \hat{Y})$ & 0.96 & 0.97 & 0.97 & 0.98 & 0.97 \\
\hline & $\begin{array}{c}\text { converge } \\
\%\end{array}$ & 98.6 & 99.0 & 85.3 & 89.1 & 96.7 \\
\hline \multirow[t]{3}{*}{ Mitscherlich } & SS(p.e.) & 146 & 141 & 347 & 1242 & 161 \\
\hline & $\operatorname{Corr}(Y, \hat{Y})$ & 0.97 & 0.97 & 0.93 & 0.74 & 0.97 \\
\hline & $\begin{array}{c}\text { converge } \\
\%\end{array}$ & 100 & 100 & 71.9 & 78.1 & 97.7 \\
\hline \multirow[t]{2}{*}{ Hoerl (Y) } & SS(p.e.) & 424 & 197 & 256 & 3602 & 3024 \\
\hline & $\operatorname{Corr}(Y, \hat{Y})$ & 0.91 & 0.96 & 0.94 & 0.57 & 0.63 \\
\hline Hoerl & SS(p.e.) & 503 & 273 & \multirow{2}{*}{\multicolumn{3}{|c|}{ no estimated computed }} \\
\hline$(\log (Y))$ & $\operatorname{Corr}(Y, \hat{Y})$ & 0.89 & 0.94 & & & \\
\hline \multirow{2}{*}{$\begin{array}{c}2^{\text {nd }} \text { order } \\
\text { Polynomial }\end{array}$} & SS(p.e.) & 807 & 546 & 481 & 1432 & 768 \\
\hline & $\operatorname{Corr}(Y, \hat{Y})$ & 0.78 & 0.86 & 0.87 & 0.60 & 0.84 \\
\hline \multirow{2}{*}{$\begin{array}{l}\text { augmented } \\
\text { Polynomial }\end{array}$} & SS(p.e.) & 545 & 491 & 382 & 1748 & 1241 \\
\hline & $\operatorname{Corr}(Y, \hat{Y})$ & 0.86 & 0.90 & 0.90 & 0.57 & 0.89 \\
\hline
\end{tabular}

1 SS (p.e.) denotes "sums of squared prediction errors" $=\sum(Y-\hat{Y})^{2}$ over 125 factor level combinations in population from which simulated data sets generated. $Y$ denotes true value, $\hat{Y}$ denotes predicted value from estimated model coefficients 
Figure 1. Visual Response of Poinsettia to Levels of N and S Applied

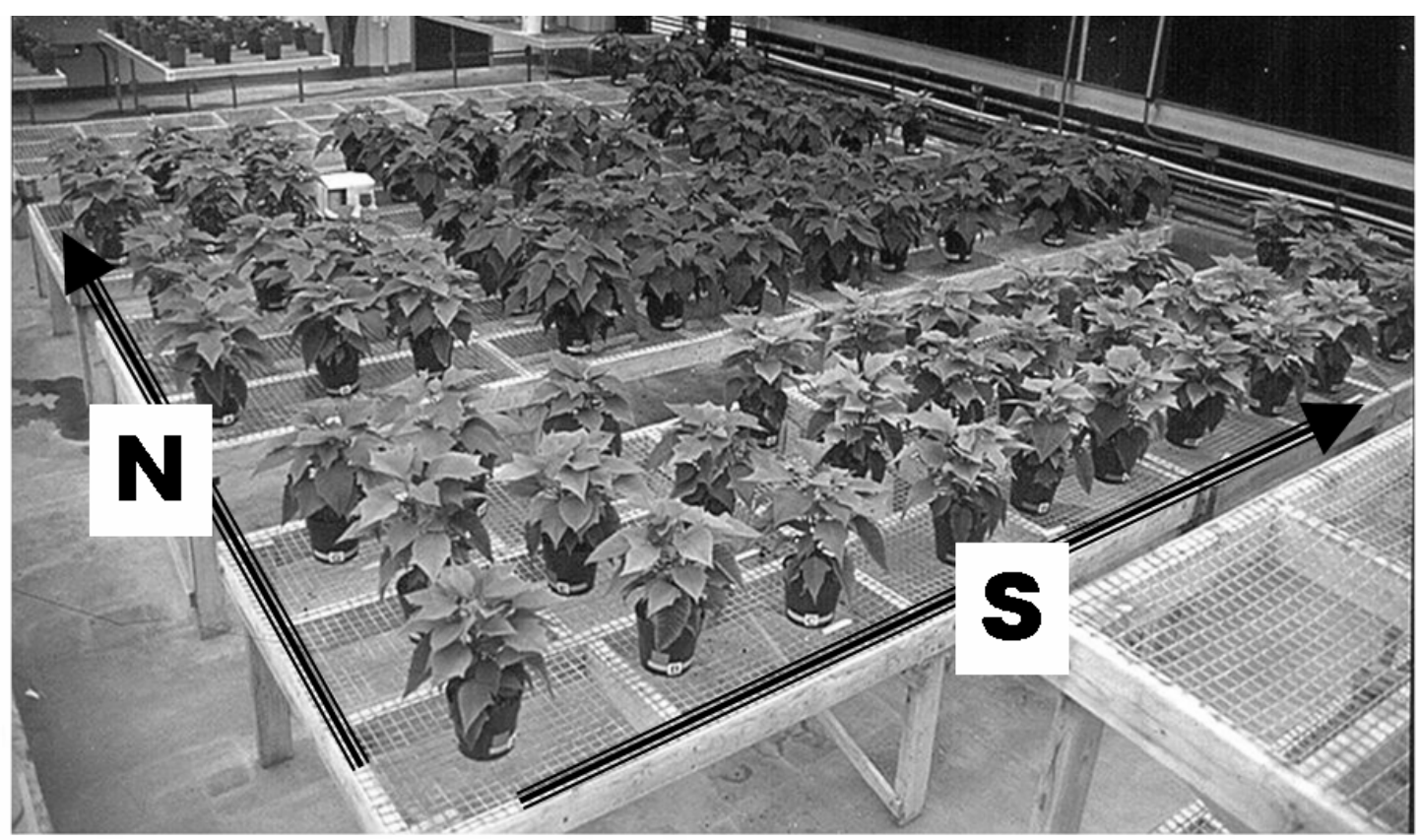


Figure 2. Plot of Poinsettia Dose-Response Profile

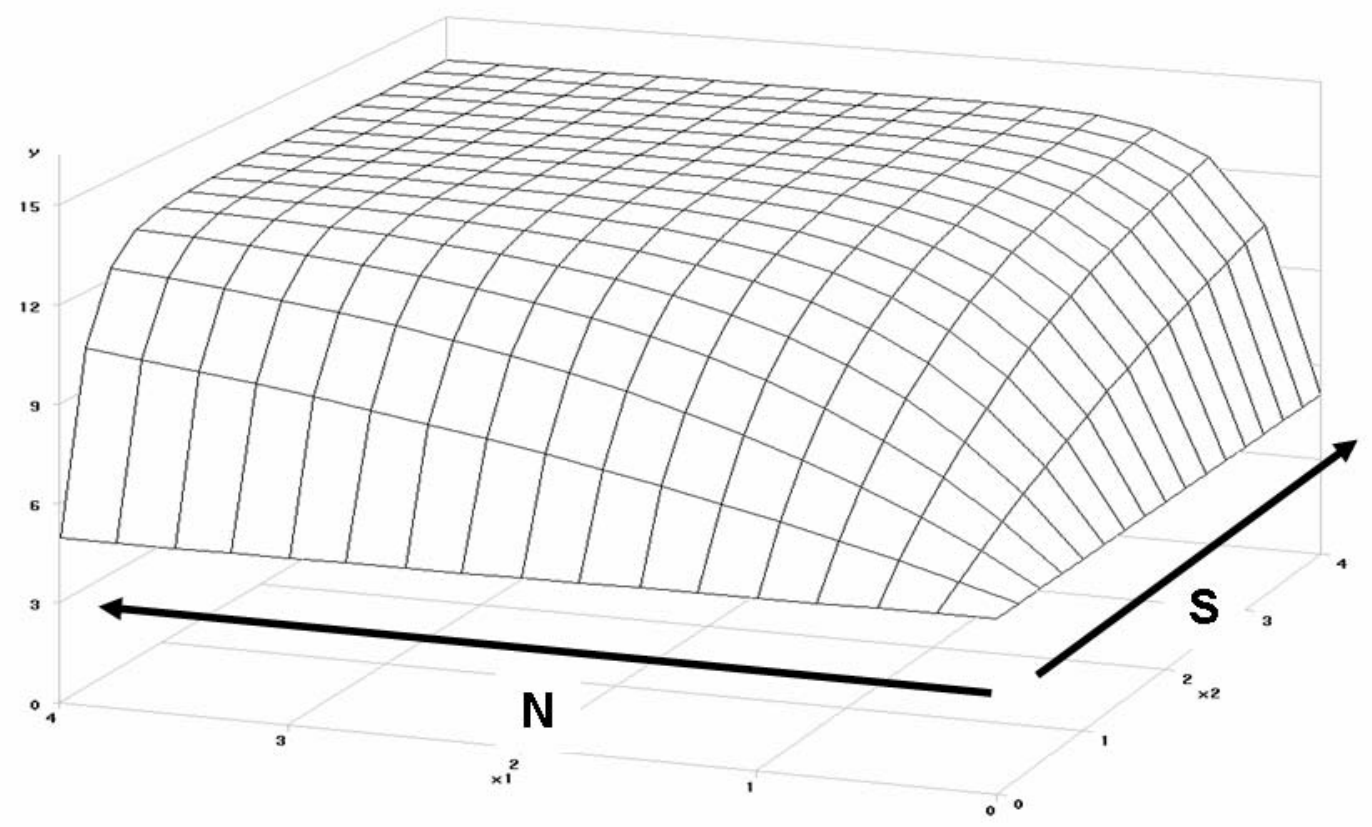


Figure 3. Quadratic Approximation of Diminishing Returns Response

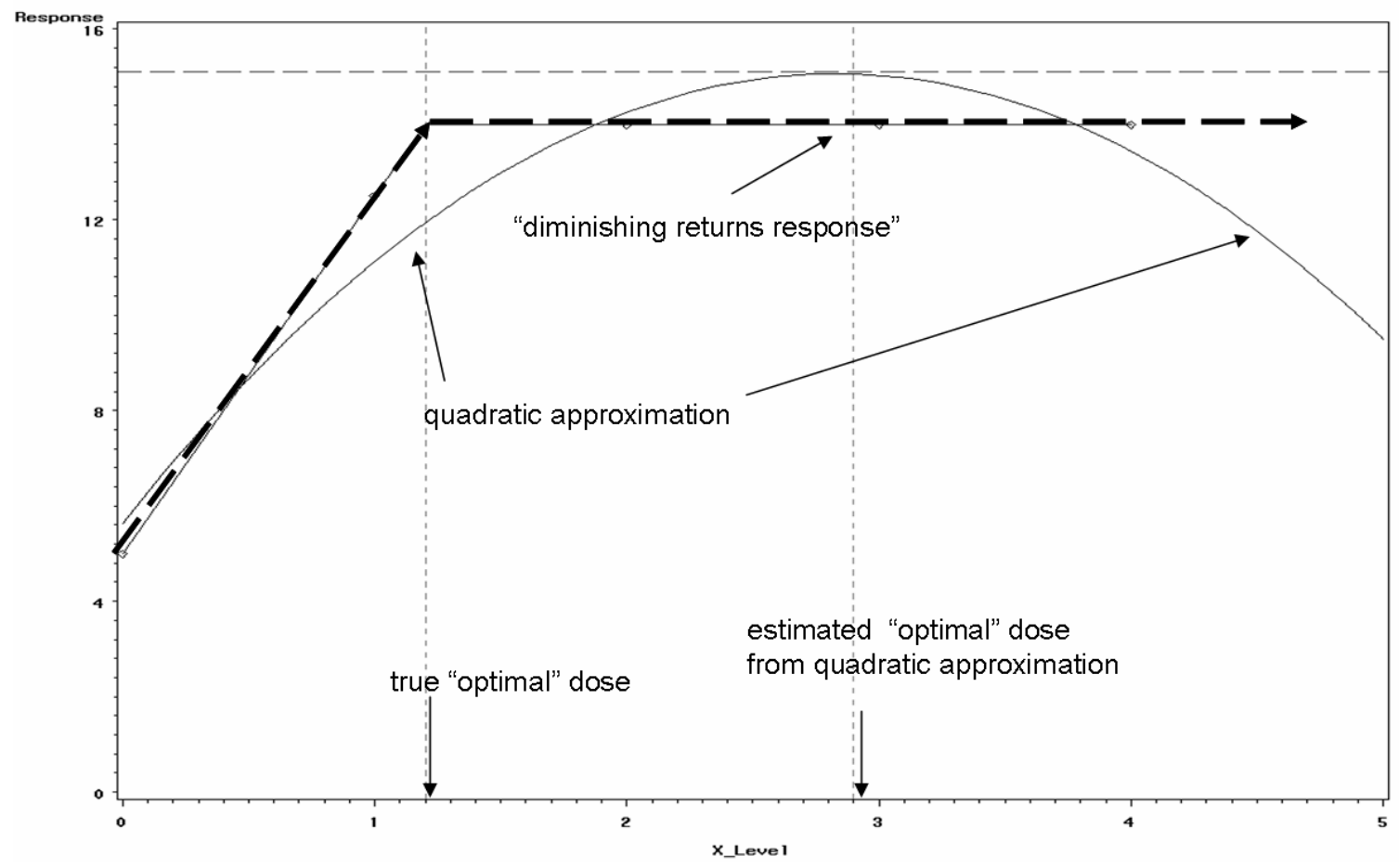


Figure 4. Gompertz and Mitscherlich Approximations of Diminishing Returns Response

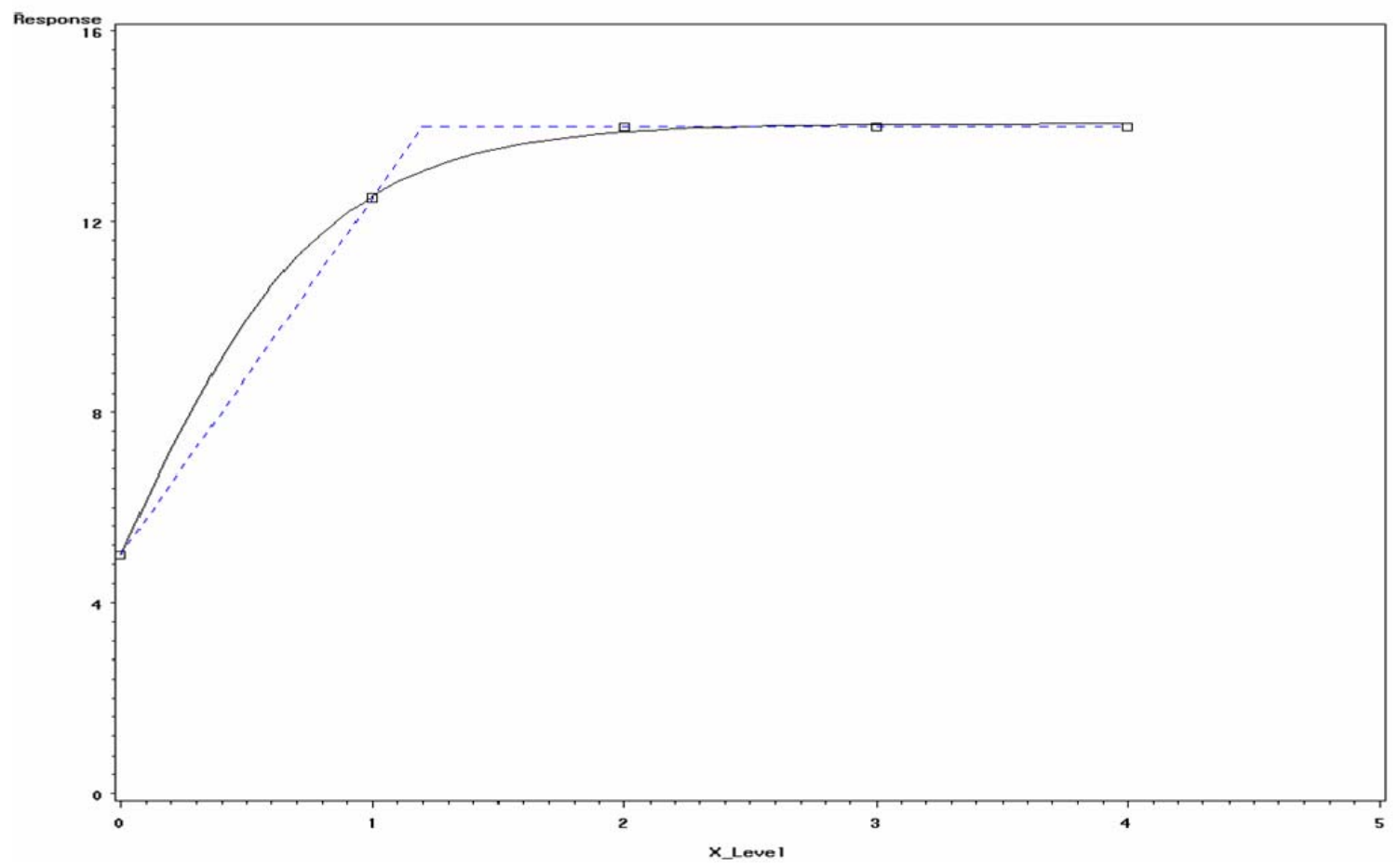


Figure 5. Hoerl Approximation of Diminishing Returns Response

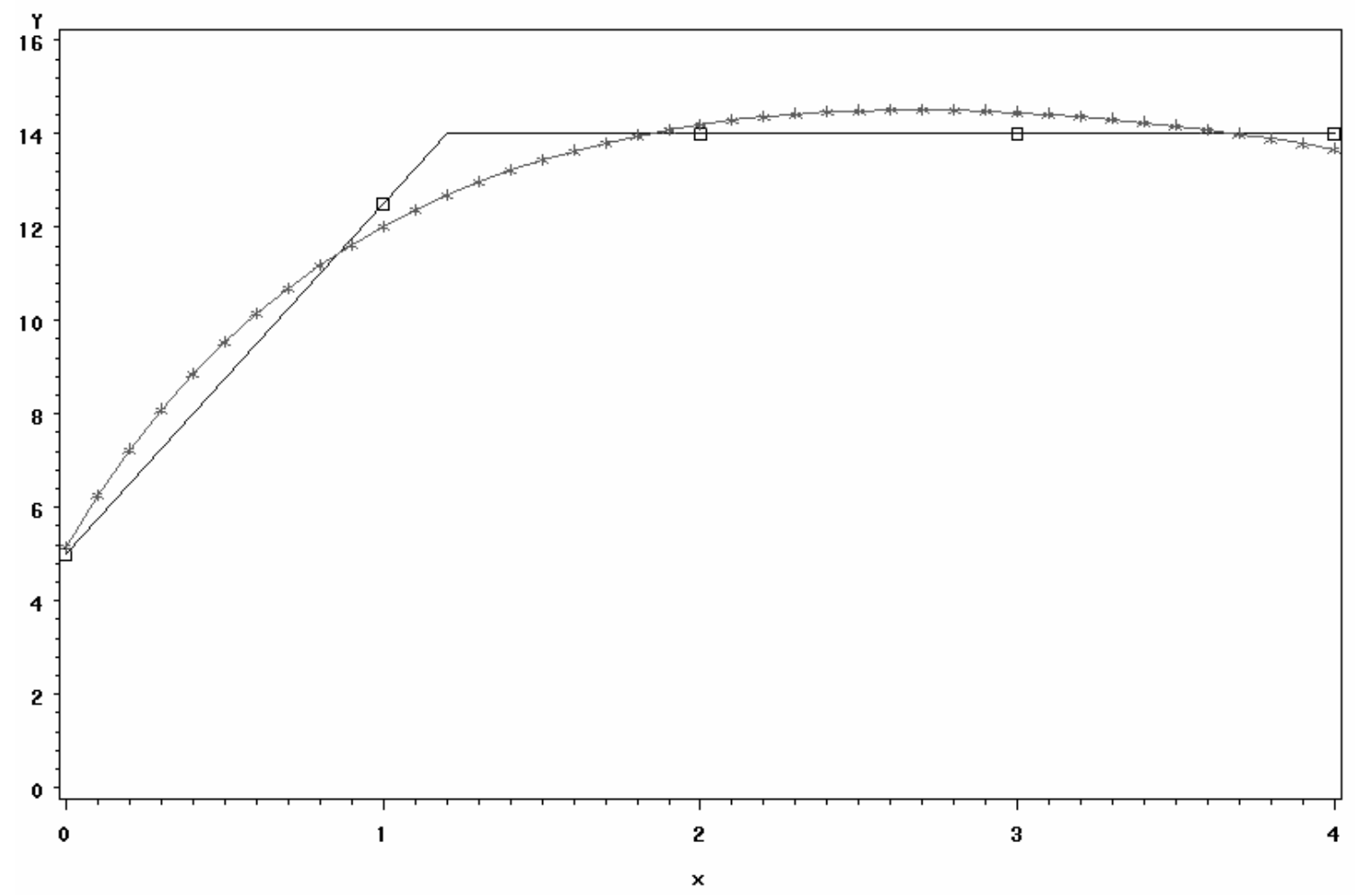


Figure 6. Olson’s “CELEPSO” Three-Factor Response Surface Design

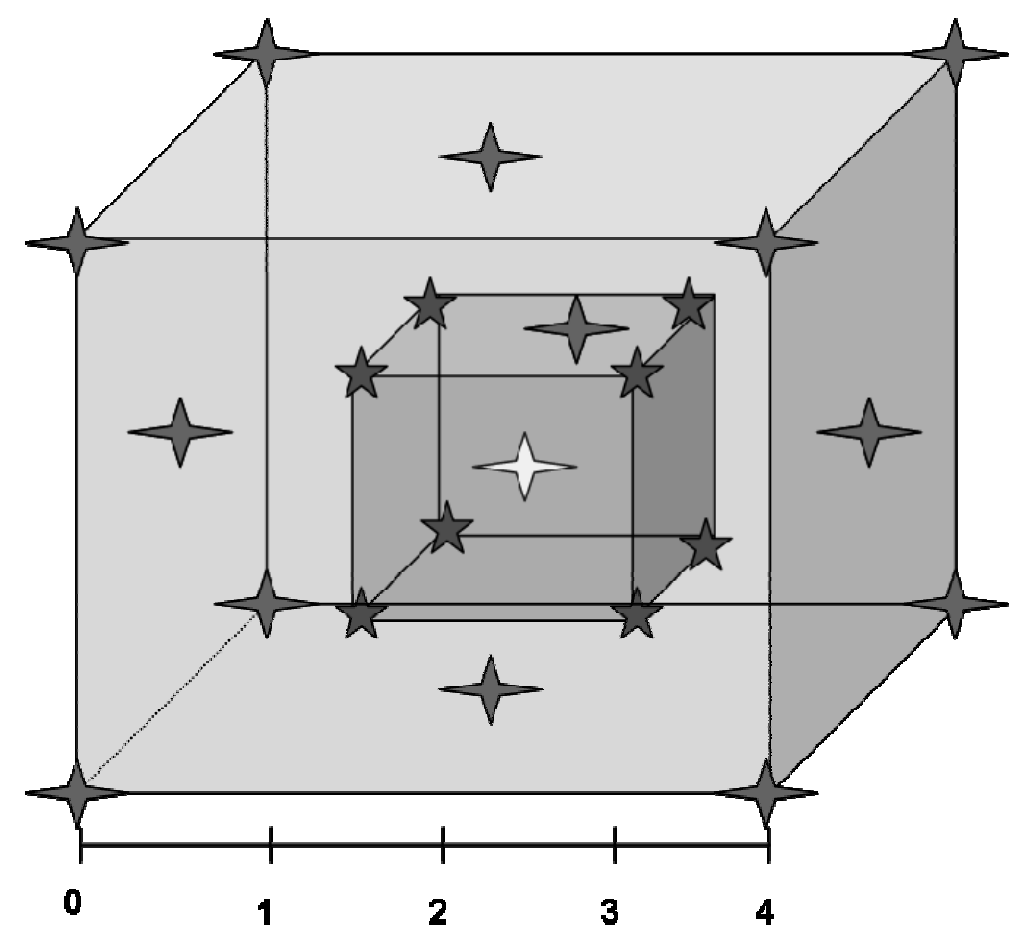




\section{This page shows Figures 7 though 9.}

Figure 7. Two-factor $2^{\text {nd }}$ Order Polynomial fit of Figure 2 Dose-Response Surface

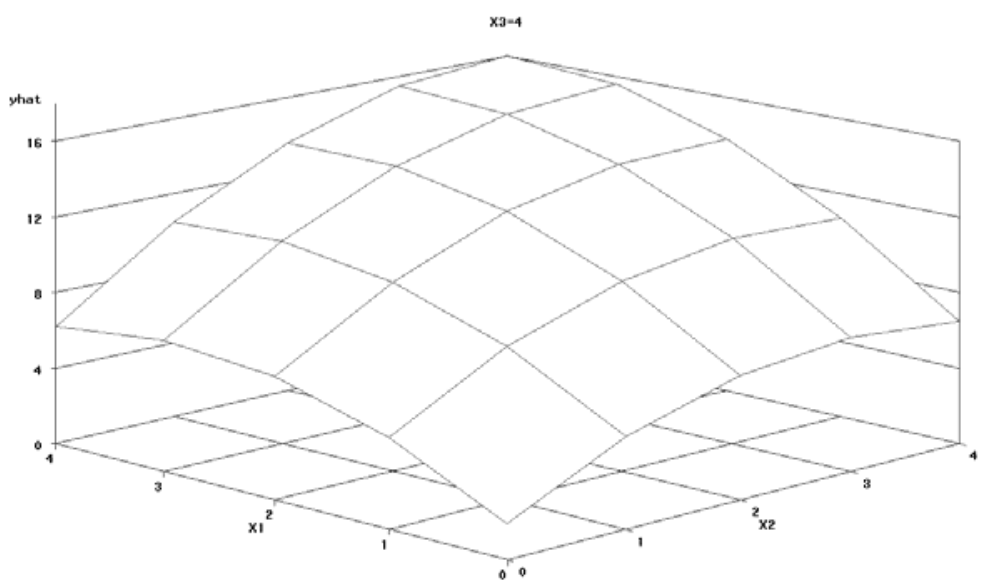

Figure 8. Two-factor Hoerl fit of Figure 2 Dose-Response Surface

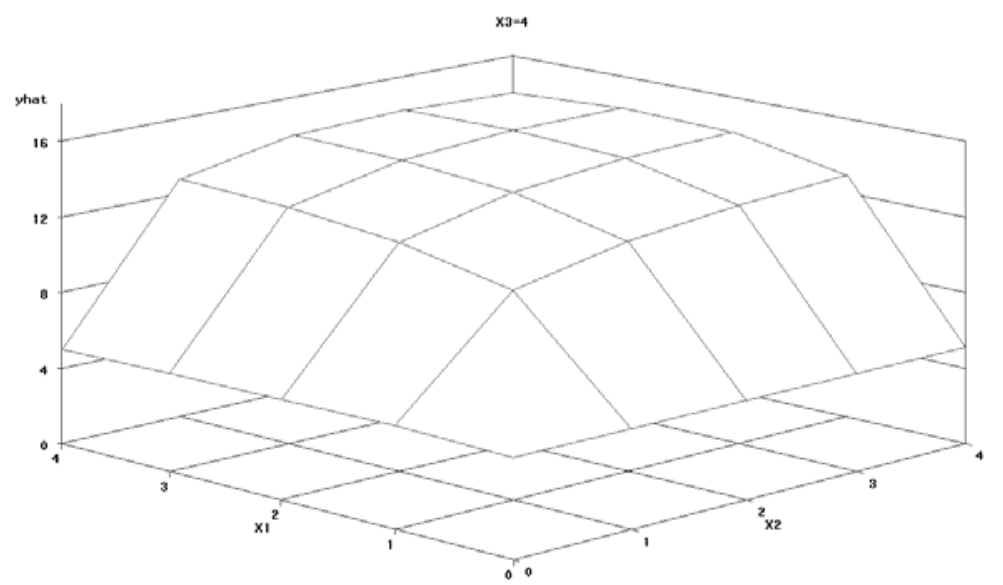

Figure 9. Two-factor Gompertz fit of Figure 2 Dose-Response Surface 


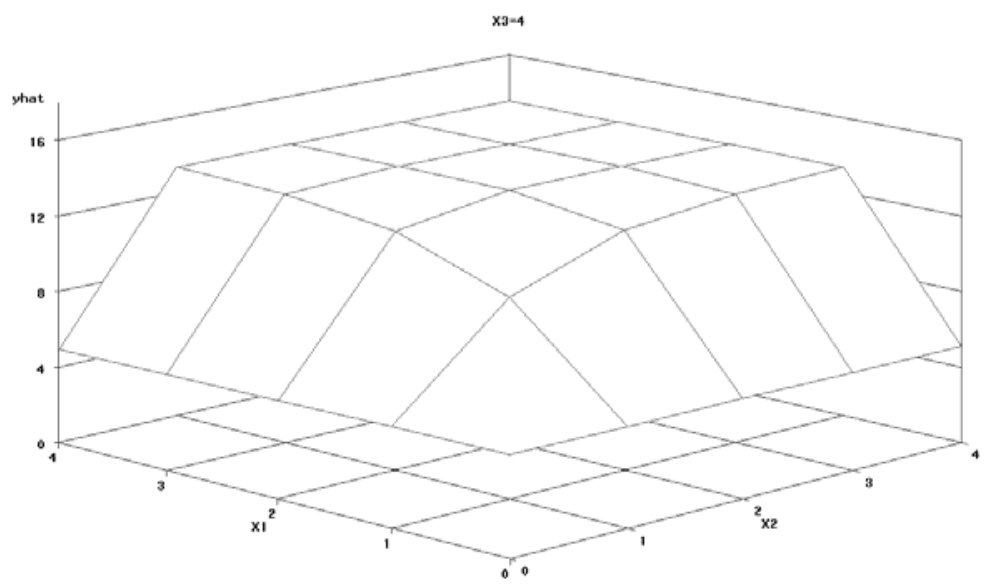


Figure 10. Two-factor augmented Polynomial fit of Figure 2 Dose-Response Surface

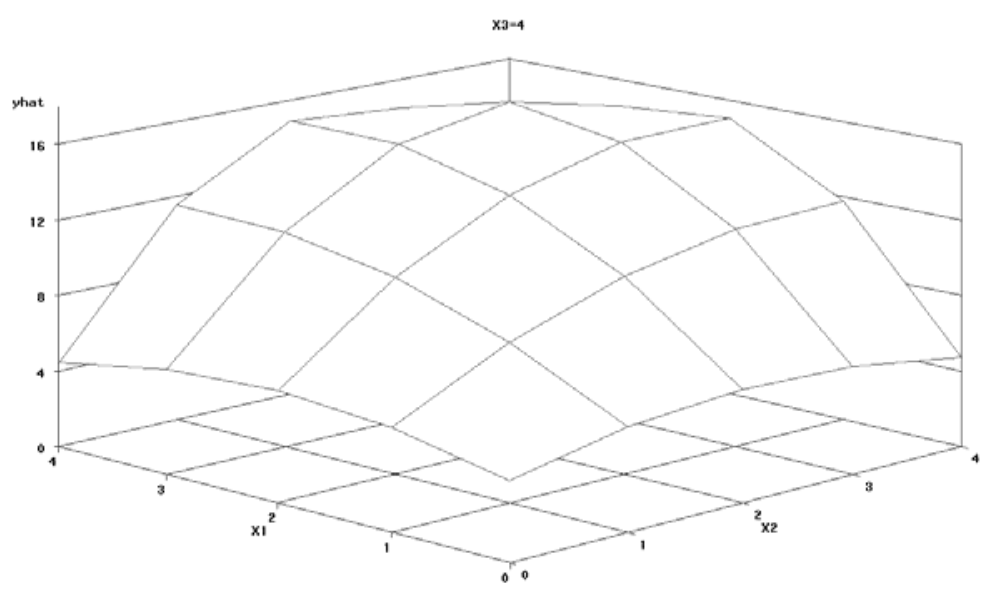


Figure 11. "Ideal” Population for Simulation Study - Three Factor “Diminishing Returns” Nonlinear Response Surface

\section{Three Way Interaction \\ Example: $5^{3}$ Factorial \\ $\mathbf{X}_{1} \times \mathbf{X}_{2}$ interaction changes for various $\mathbf{X}_{3}$}

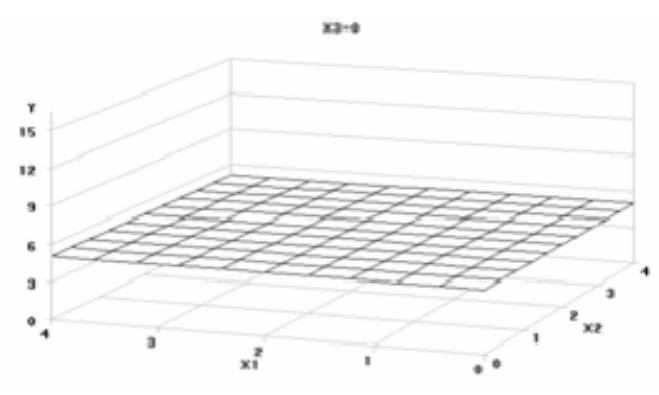

at $\mathbf{X}_{3}=\mathbf{0}$

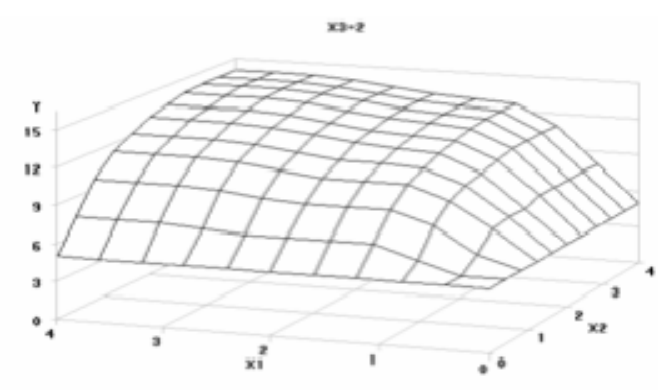

at $\mathbf{X}_{3}=2$

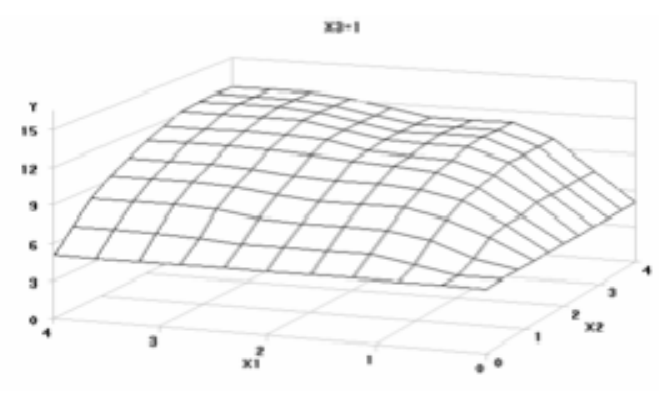

at $\mathbf{X}_{3}=1$

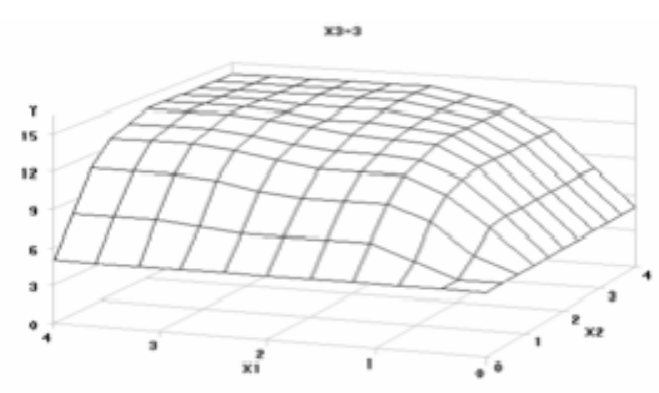

at $\mathbf{X}_{3}=\mathbf{3}$

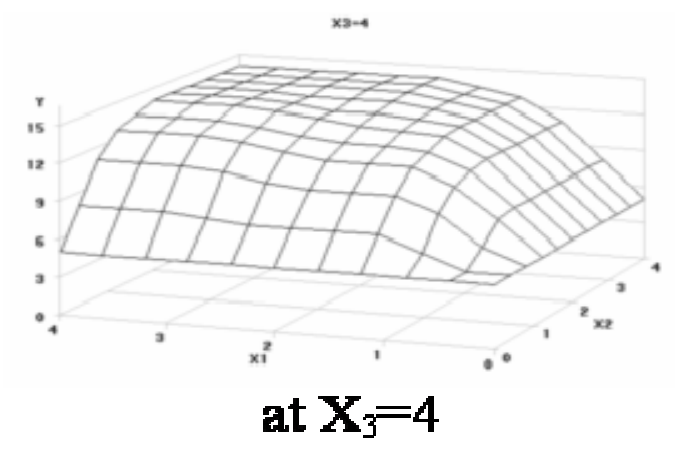


This page shows Figures 12 and 13.

Figure 12. Average fit of Mitscherlich model estimated from D-optimal wrt Hoerl design at $\mathrm{X} 3=0$

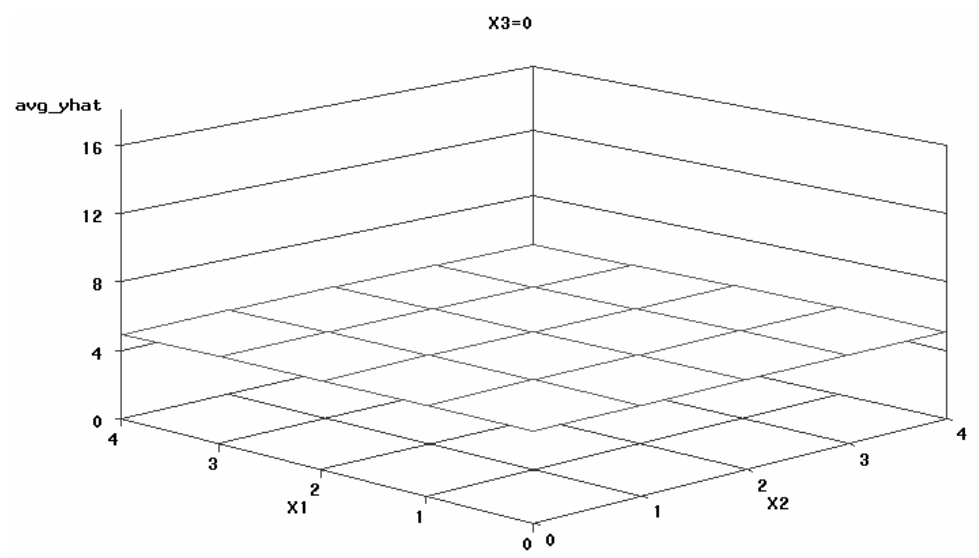

Figure 13. Average fit of Mitscherlich model estimated from D-optimal wrt Hoerl design at $\mathrm{X} 3=4$

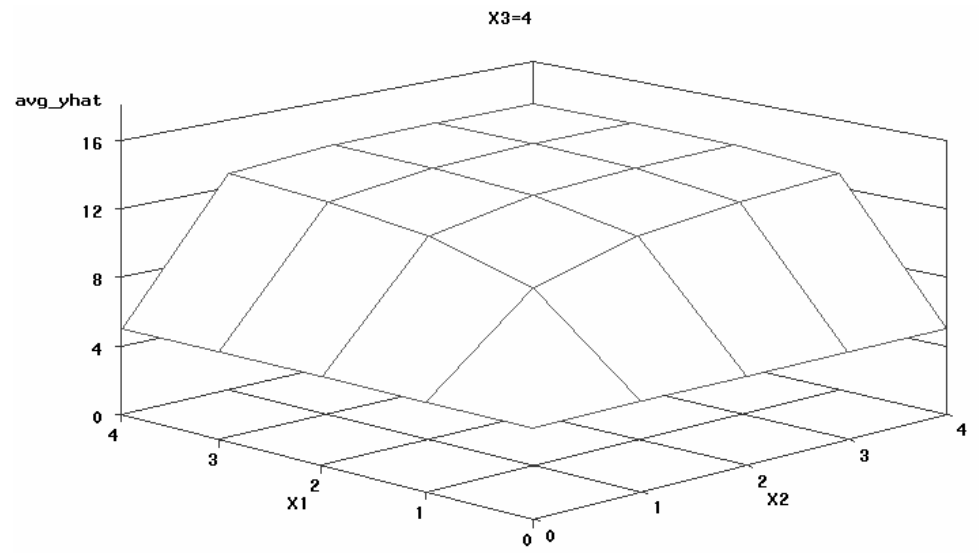




\section{This page shows Figures 14 and 15.}

Figure 14. Average fit of Hoerl model estimated from D-optimal wrt Hoerl design at X3=0

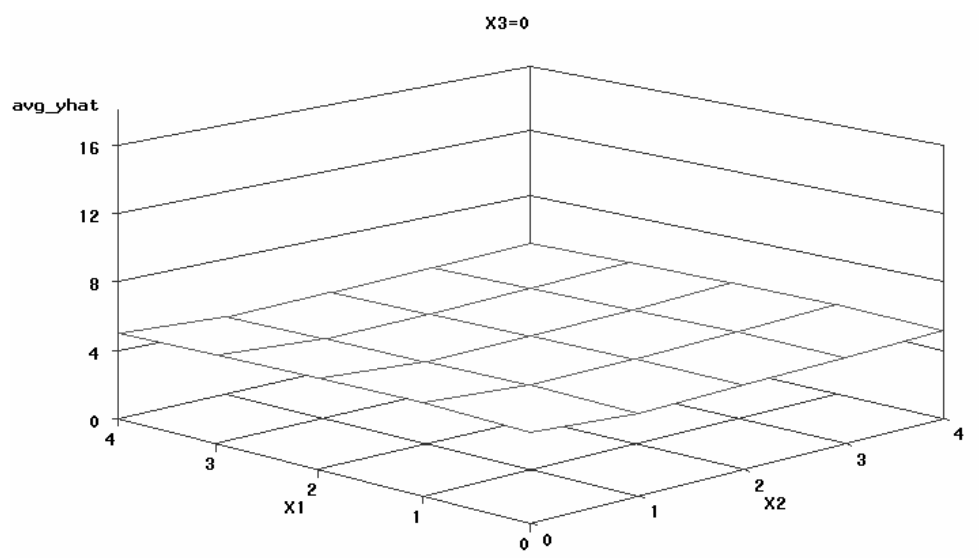

Figure 15. Average fit of Hoerl model estimated from D-optimal wrt Hoerl design at X3=4

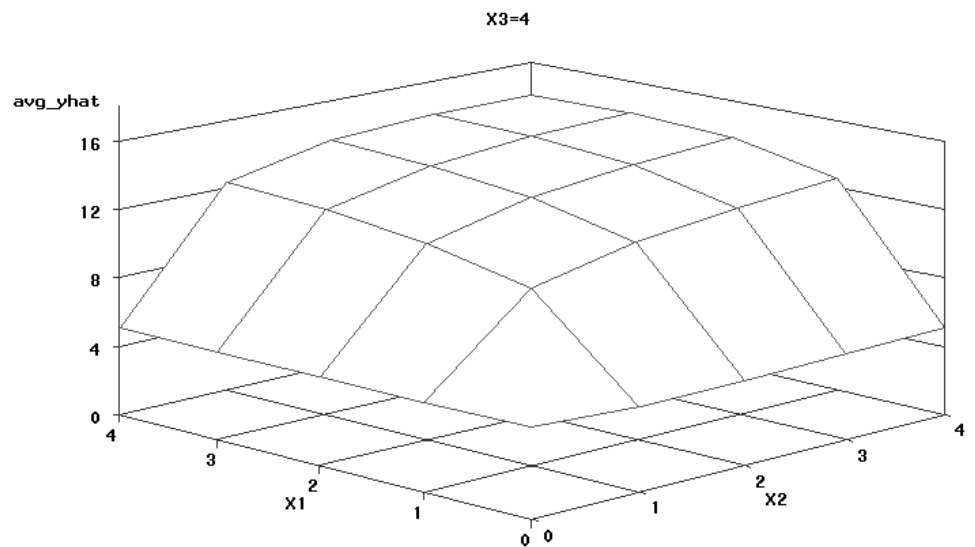




\section{This page shows Figures 16 and 17.}

Figure 16. Average fit of Hoerl model estimated from D-optimal wrt Hoerl design at $X 3=0$

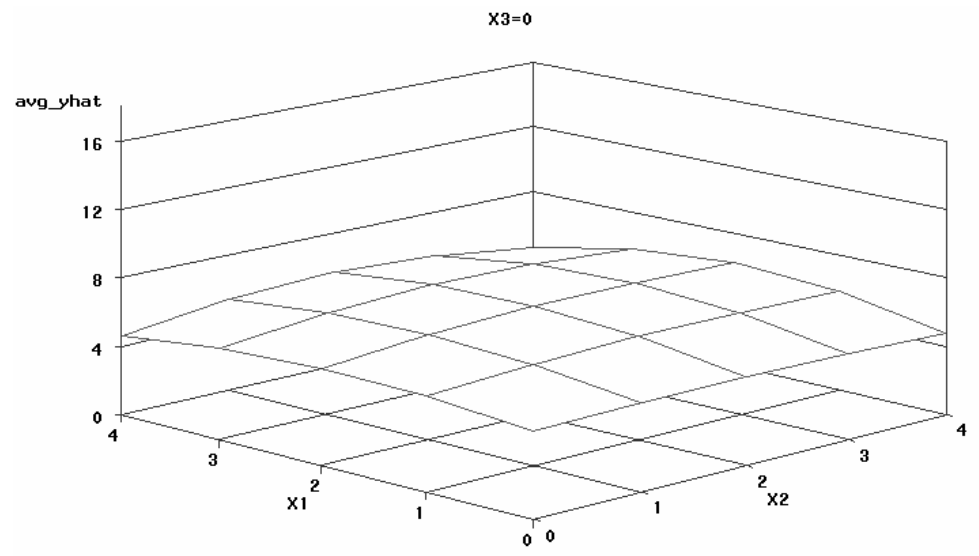

Figure 17. Average fit of Hoerl model estimated from D-optimal wrt Hoerl design at $X 3=0$

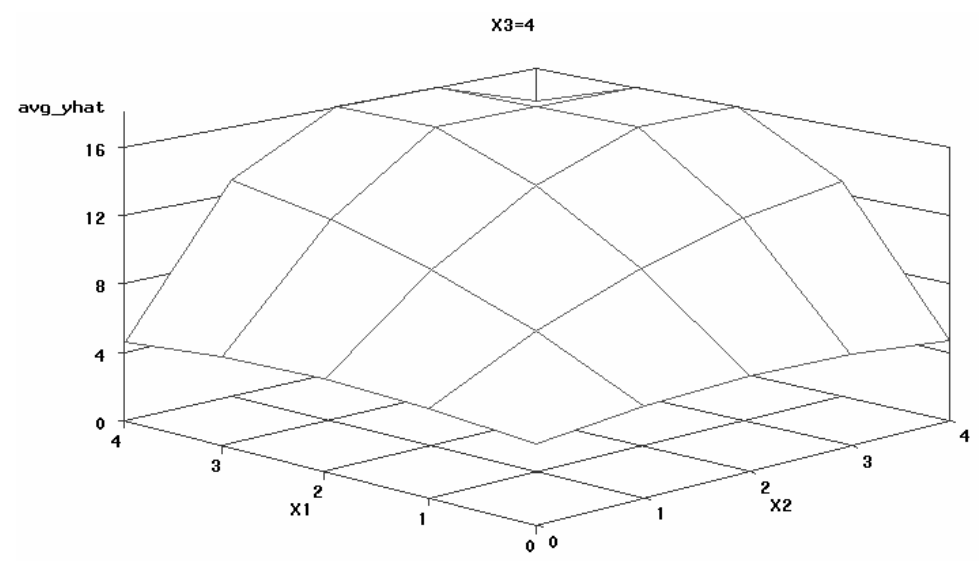

